\title{
ANALISIS HASIL SURVEI BATIMETRI DAN ARUS DI PELABUHAN JAMPEA KABUPATEN SELAYAR
}

\author{
Syatir Suaib ${ }^{1)}$, Ahmad Alieffathur Rusvan ${ }^{2)}$, A. Imran Anshari ${ }^{3)}$ \\ ${ }^{1}$ Politeknik Pertanian Negeri, Indonesia \\ E-mail: syatirsuaib2018@gmail.com \\ ${ }^{2}$ Politeknik Pertanian Negeri, Indonesia \\ Email :ahmad_aliffathur@gmail.com \\ ${ }^{3}$ Politeknik Pertanian Negeri, Indonesia \\ Email : imrananshari@gmail.com
}

\begin{abstract}
ABSTRAK
Survei Batimetri dan Arus dilakukan untuk mengetahui peta batimetri dan pola arus disekitar pelabuhan Jampea. Hasil penelitian ini diharapkan dapat memberikan gambaran hasil pengujian di lapangan dengan hasil uji numerik pada data yang akan diolah. Penelitian dilaksanakan pada bulan Juni hingga bulan Agustus 2019 di perairan pelabuhan Jampea Kabupaten Selayar. Metode yang digunakan adalah kuantitatif. Pengambilan data pemeruman dengan Echosounder Singlebeam Garmin GPS MAP 178C. Sedangkan pengukuran arus dilaksanakan 2 kali, yaitu pada saat pasang tertinggi (spring tide) dan terendah (neap tide). Penyajian data ditampilkan dengan software SMS 10.0 (Surface water modeling system). Dari hasil pengukuran dilapangan bahwa arus menjelang pasang memiliki kecepatan rata-rata adalah $0,044 \mathrm{~m} / \mathrm{s}$, pada saat pasang inilah arus laut mengarah ke arah tenggara. Sementara itu, pada saat menjelang surut, kecepatan arus rerata adalah $0,08 \mathrm{~m} / \mathrm{s}$ dan mengarah ke barat laut. Sedangkan pada hasil analisa software SMS.10 dimana pada saat surut, arus di sekitar lokasi studi dominan bergerak dari tenggara ke barat laut dengan kecepatan rerata 0,009 $\mathrm{m} /$ detik dan pada saat pasang di sekitar daerah studi arus bergerak dari barat laut menuju ke tenggara dengan kecepatan rerata yaitu 0,0084 m/detik. Kondisi batimetri pada areal sekitar pelabuhan Jampea termasuk kategori pantai yang landai dimana pesisir atau tepi laut yang daratannya menurun sedikit demi sedikit ke arah laut yang mengakibatkan pengaruh pasang surut sangat jauh keluar menuju ke laut.
\end{abstract}

Kata Kunci: Analisis, Batimetri, Arus, Jampea

\section{ABSTRACT}

The bathymetry and flow survey was conducted to find out bathymetry maps and flow patterns around the port of Jampea. The results of this study are expected to provide an overview of the results of testing in the field with numerical test results on the data to be processed. The study was conducted in June to August 2019 in the waters of the port of Jampea, Selayar Regency. The method used is quantitative. The data used in the study are singlebeam acoustic system Garmin GPS MAP 178C. Current measurements are carried out 2 times, namely at the highest tide (spring tide) and lowest (neap tide). Presentation of data is displayed with the SMS 10.0 (Surface water modeling system) software. From the results of measurements in the field that the current before the tide has an average speed of $0.044 \mathrm{~m} / \mathrm{s}$, it is at this tide that the ocean current is heading southeast. Weak currents are unable to move the basic sediments, unless the sediment is floating. Bathymetry conditions in the area around the port of Jampea are categorized as a sloping beach where the coastline or the shore of the land Meanwhile, on the eve of receding, the average current velocity is $0.08 \mathrm{~m} / \mathrm{s}$ and it heads northwest. Whereas the results of the analysis of the SMS software 10 where at low tide, the currents around the study location predominantly move from southeast to northwest at an average speed of $0.009 \mathrm{~m} / \mathrm{s}$ and at high tide around the study area the current moves from the northwest to southeast at a speed the mean is $0.0084 \mathrm{~m} / \mathrm{s}$. Bathymetry conditions in the area around the port of Jampea are categorized as a sloping beach where the coastline or the shore of the land decreases gradually towards the sea resulting in tidal effects very far out to sea

Keywords: Analysis, Bathymetry, Flow, Jampea 


\section{Pendahuluan}

Kabupaten Selayar merupakan salah satu kabupaten di Provinsi Sulawesi Selatan yang memiliki wilayah pesisir pantai. Wilayah pesisir ini memiliki arti penting bagi masyarakat Selayar khususnya di Pulau Jampea karena selain memiliki keanekaragaman yang tinggi juga merupakan aktivitas ekonomi seperti sebagai wilayah rekreasi, budidaya perikanan dan rumput laut. Namun saat ini abrasi dan sedimentasi pantai di Pulau Jampea terkhusus di Pelabuhan Jampea telah mencapai tingkat yang mengkhawatirkan. Jika tidak disediakan pencegahan terhadap abrasi air laut ini maka akan terjadi degradasi sistem alamiah yang berujung pada terjadinya perubahan garis pantai. Pemukiman warga, fasilitas umum dan fasilitas sosial terancam akan tergerus apabila tidak segera dilakukan penanganan.

Surf zone merupakan lokasi terjadinya aktivitas angkutan sedimen di daerah pantai. Maju mundurnya posisi garis pantai sangat tergantung pada laju dan arah angkutan sedimen di surf zone (Prayitno,2014). Besar dan arah angkutan sedimen sangat tergantung pada laju dan arah arus di surf zone. Arus di surf zone umumnya terjadi akibat induksi gelombang (wave induced current). Pada pantai yang cenderung mengalami abrasi maka arus gelombang pada daerah ini secara kontinu membawa sedimen dan di pindahkan pada ruas pantai yang lain. Informasi tentang batimetri suatu perairan memberikan banyak manfaat baik secara langsung maupun tidak langsung, apalagi dihadapkan pada kondisi perairan Indonesia yang luas dengan banyaknya pulau - pulau kecil. Manfaat tersebut diantaranya untuk kepentingan militer, navigasi serta perencanaan dan manajemen pesisir (Bagus, 2013).

Atas dasar pertimbangan tersebut di atas maka kami akan melakukan survey terkait kondisi bathimetri dan arus saat ini yang nantinya akan kami modelkan kedalam numerik sehingga pola arus yang disekitar pelabuhan Jampea sebagai data awal atau data pembanding dalam pedoman penanggulangan masyarakat sekitar Pelabuhan Jampea.

\section{Metodologi}

\section{Materi Penelitian}

Survei batimetri dilakukan dengan cakupan daerah perairan yang menjadi wilayah studi. Alur pelaksanaan pemeruman hingga penggambaran hasil, dapat dilakukan mengikuti bagan alir pada Gambar berikut.

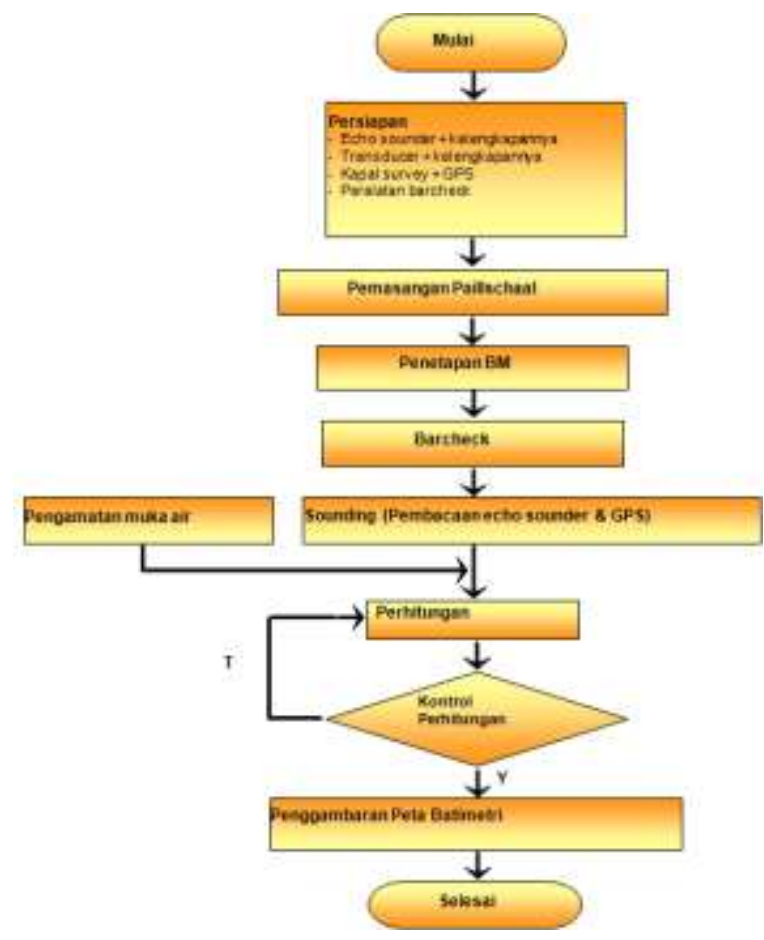

\section{Persiapan}

Dalam pekerjaan persiapan ini dilakukan kalibrasi alat dan setting peralatan diatas kapal motor, sebelum kapal berangkat peralatan di coba dan diukur kedalaman titik dengan papan skala, jika terdapat perbedaan maka perlu dicatat untuk koreksi. Pemeruman dilakukan dengan interval berkisar $15 \mathrm{~m}$ sampai $25 \mathrm{~m}$, pemeruman dilakukan dengan lebih rapat pada posisi dekat dengan garis pantai, hal ini dilakukan karena perencanaan bangunan pengaman pantai biasanya sangat dekat dengan pantai sehingga perhitungan ketelitian dan volume pekerjaan bangunan akan lebih baik.

\section{Penenetuan Titik Ikat Posisi Horisontal}

Posisi titik ukur kedalaman dikendalikan dengan alat Global Positioning System (GPS). Metode pembacaan koordinat dapat dilihat pada Gambar 2. 


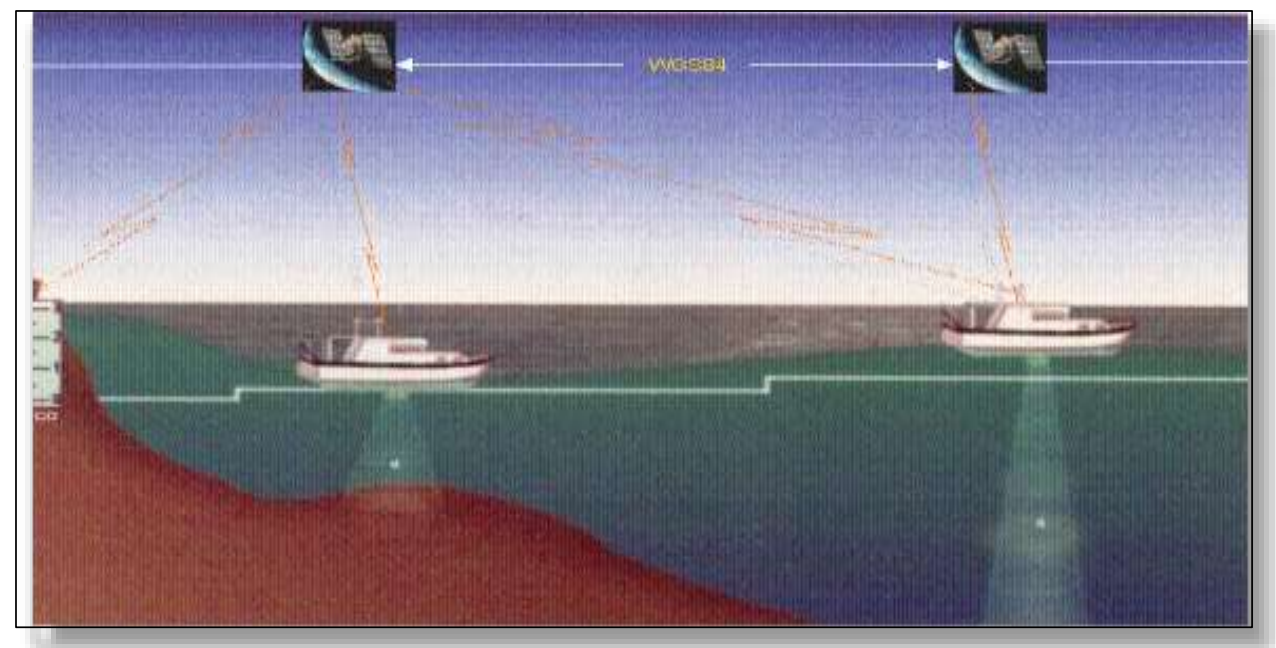

Gambar 2. Metode pembacaan koordinat horisontal dan kedalaman laut

\section{a) Haluan Pemeruman}

Haluan pemeruman yang dilaksanakan semaksimal mungkin tegak lurus dengan garis air tepi waduk atau antar lintasan sejajar seperti yang dilakukan oleh Dewi dkk (2015) dan Haryono (2001),haluan pemeruman tersebut dapat dilihat pada Gambar 2.3. Sedangkan untuk pengukuran arus dimana pertama-tama, membuat alat ukur arus berupa floater yang terbuat dari papan dan balok kayu. Alasan penggunaan material kayu karena material tersebut dapat mengapung dan mudah dibentuk sesuai kebutuhan. Pada floater dipasang botol plastik untuk menyimpan GPS. Setelah peralatan pengukuran siap, selanjutnya alat survei dibawah ke posisi pengukuran dengan menggunakan perahu. Floater yang telah dilengkapi dengan GPS dilepas dan floater akan bergerak mengikuti arah arus. Posisi floater setiap saat akan terekam oleh GPS. Setelah waktu pengukuran dianggap selesai, selanjutnya floater diambil dengan menggunakan perahu. Pengukuran arus dilaksanakan 2 kali, yaitu pada saat pasang tertinggi (spring tide) dan terendah (neap tide).

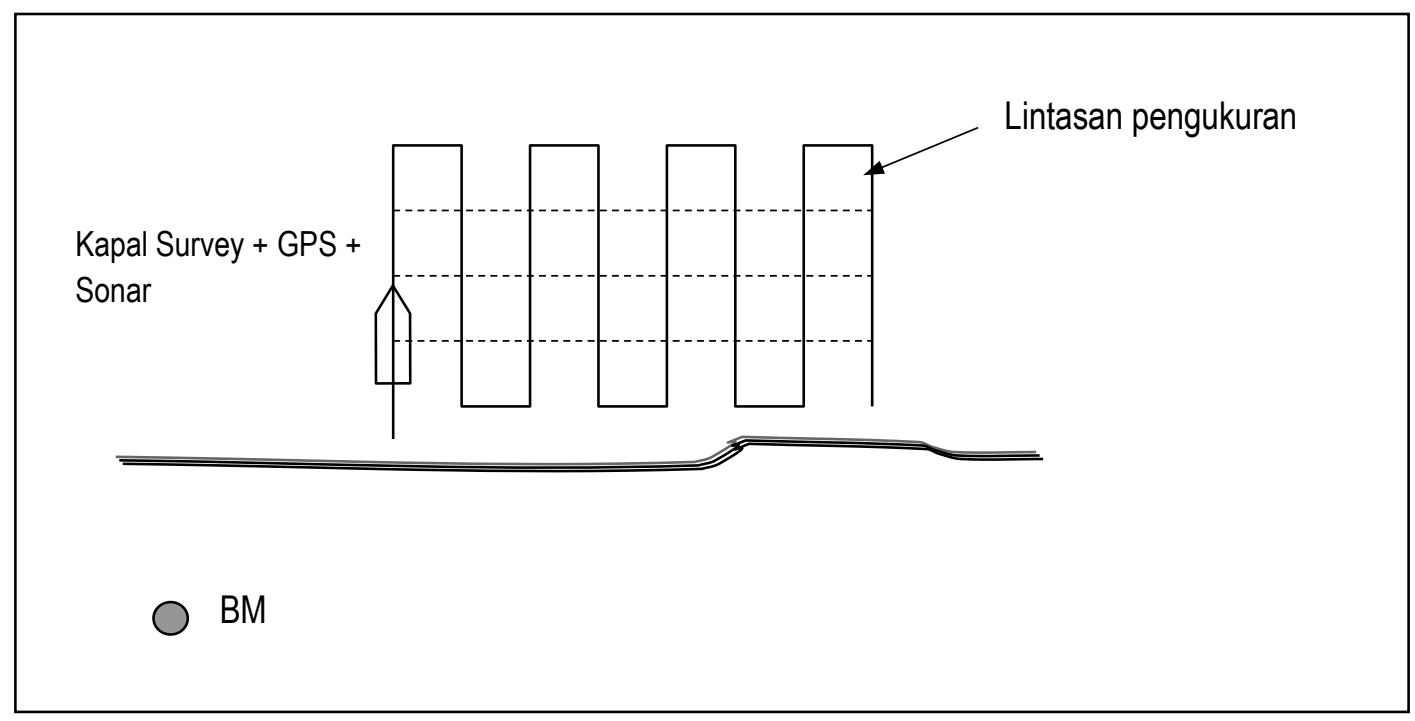

Gambar 3. Lintasan Pemeruman 


\section{Pengambilan Data}

Sebelum dilakukan pengukuran posisi titik dan kedalaman dasar pantai, alat-alat dipersiapkan terlebih dahulu dipasang dengan bantuan beberapa peralatan lainnya. Setelah semua alat dipasang, pengukuran dapat dilakukan. Titik awal dan titik bantu dari pengukuran ditentukan terlebih dahulu dari peta yang kemudian diplot di GARMIN GPSMAP 178C Sounder. Ketika pengukuran berlangsung, di layar alat GARMIN tampak jalur yang harus dilalui, sehingga batas wilayah yang diukur dan interval jalur pengukuran bisa terlihat di layar monitor. Data bathimetri yang didapat dari pengukuran, selanjutnya diikat pada bacaan elevasi muka air dari pengamatan pasang surut untuk waktu yang sama. Untuk survei arus pada penelitian ini dilakukan pada 2 titik atau dua lokasi, baik pada kondisi surut maupun pada kondisi pasang

\section{Hasil dan Pembahasan \\ Analisis Batimetri dan Arus di Sekitar Pelabuhan Jampea}

Akibat adanya gerakan massa air oleh pasang surut, maka akan terjadi arus yang dinamakan arus pasang surut. Arus pasang surut ini berpotensi mengakibatkan terjadinya sedimentasi di suatu tempat tertentu, dimana kecepatan arus sangat kecil. Kajian sirkulasi arus di lokasi pelabuhan Jampea bahwa timbulnya arus-arus permukaan yang terbentuk lebih banyak didominasi oleh arus pasut karena disamping lokasinya yang sempit juga mencirikan kondisi batimetri bawah laut yang cukup dangkal sehingga lebih banyak di pengaruhi oleh arus pasang surut. Kondisi dasar laut pelabuhan Jampea dapat dilihat pada Gambar 4.
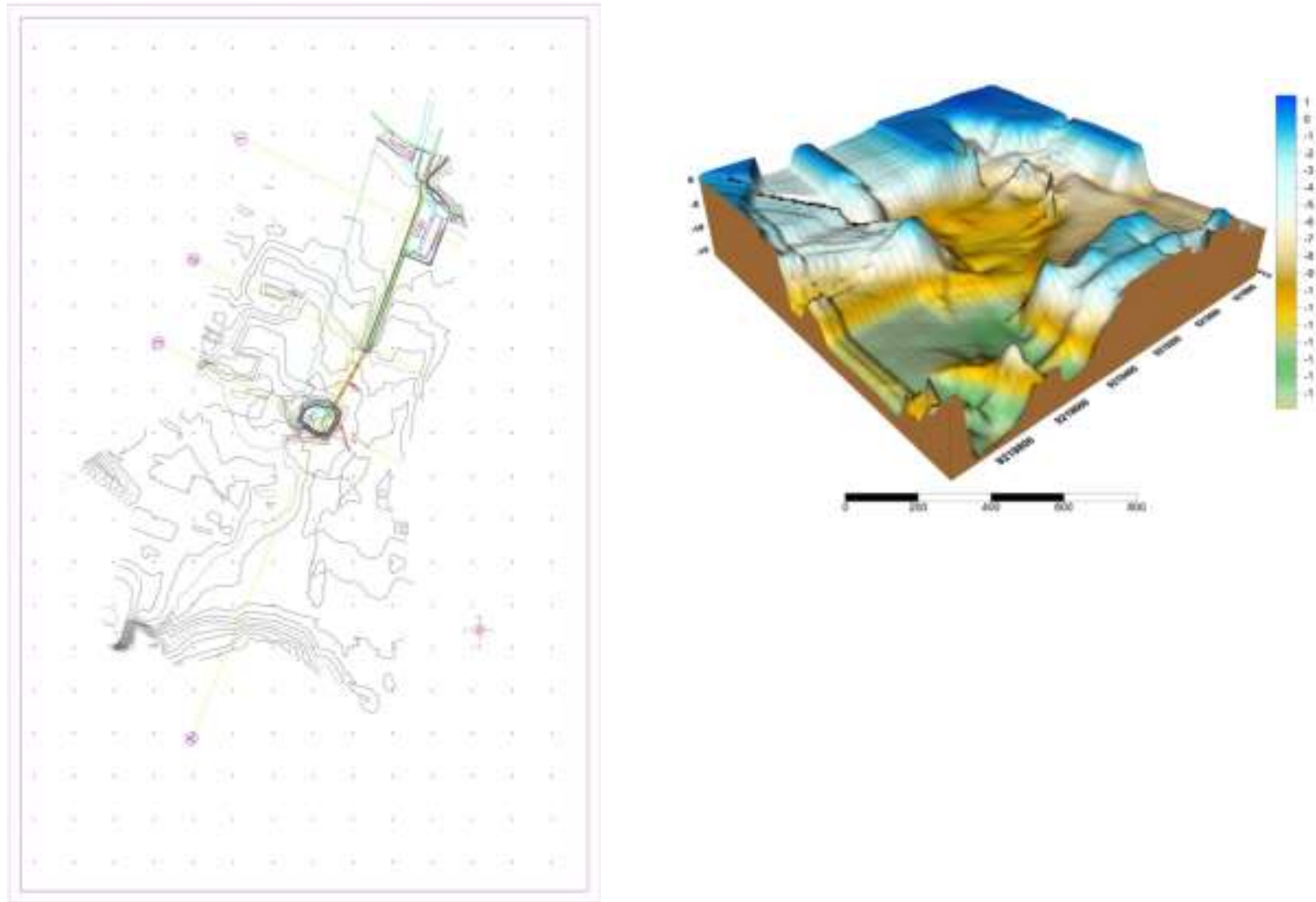

Gambar 4. Kondisi Bathimetri di Sekitar Pelabuhan Jampea dan Skala 3 D

(Sumber: Hasil Pengolahan data Autocad Civil dan Surfer 10))

Hasil pengukuran arus tertera pada Tabel dibawah (Tabel1) dimana kecepatan arus memperlihatkan bahwa kecepatan rata-rata aliran air akibat pasang surut di lokasi studi 
cukup lemah, yakni rata-rata $0.08 \mathrm{~m} / \mathrm{s}$ atau. Kecepatan arus yang lemah tidak mampu untuk menggerakkan sedimen dasar, kecuali sedimen melayang. Hal ini dijelaskan oleh Siebold dan Berger (1993) bahwa kecepatan arus dapat mempengaruhi pergerakan sedimen, dimana ukuran butir sedimen $1 \mathrm{~mm}$ dapat bergerak jika kecepatan arus minimal sebesar $0,5 \mathrm{~m} /$ detik.

Tabel 1 Data Pengukuran Arus disekitar Pelabuhan Jampea

\begin{tabular}{|c|c|c|c|c|c|c|c|c|c|}
\hline \multirow[b]{3}{*}{ No } & \multicolumn{4}{|c|}{ Koordinat } & \multicolumn{2}{|c|}{ Waktu } & \multirow{3}{*}{$\begin{array}{l}\text { Selisih } \\
\text { (detik) }\end{array}$} & \multirow{3}{*}{$\begin{array}{c}\text { Jarak } \\
\begin{array}{c}\text { Perpindahan } \\
\text { Meter }\end{array} \\
\end{array}$} & \multirow{3}{*}{$\begin{array}{l}\text { Kecepatan } \\
\text { Arus }(\mathrm{m} / \mathrm{d})\end{array}$} \\
\hline & \multicolumn{2}{|c|}{ TITIK AWAL } & \multicolumn{2}{|c|}{ TITIK AKHIR } & \multirow{2}{*}{$\begin{array}{l}\text { Jam } \\
\text { Awal }\end{array}$} & \multirow{2}{*}{$\begin{array}{c}\text { Jam } \\
\text { Akhir }\end{array}$} & & & \\
\hline & $x$ & $\mathrm{Y}$ & $x$ & $\mathrm{Y}$ & & & & & \\
\hline 1 & 236078 & 9219148 & 235937 & 9219156 & 10.08 & 10.38 & 1080 & 141.2 & 0.131 \\
\hline 2 & 235540 & 9219273 & 235690 & 9219349 & 10.21 & 11.21 & 3600 & 168.2 & 0.047 \\
\hline 3 & 235929 & 9219187 & 235778 & 9219241 & 10.43 & 11.17 & 2664 & 160.4 & 0.06 \\
\hline 4 & 236151 & 9219165 & 236067 & 9219185 & 14.07 & 14.37 & 1080 & 86.3 & 0.08 \\
\hline 5 & 236281 & 9219169 & 236173 & 9219096 & 14.13 & 14.43 & 1080 & 130.4 & 0.121 \\
\hline 6 & 236429 & 9219148 & 236353 & 9219350 & 14.47 & 15.11 & 2304 & 96.2 & 0.042 \\
\hline 7 & 236182 & 9219328 & 236086 & 9219350 & 14.53 & 15.24 & 2556 & 98.5 & 0.039 \\
\hline 8 & 235822 & 9219143 & 235709 & 9219135 & 15.3 & 15.59 & 1044 & 113.3 & 0.109 \\
\hline 9 & 235710 & 9218953 & 235689 & 9218918 & 15.36 & 16.05 & 2484 & 40.8 & 0.016 \\
\hline 10 & 235765 & 9218782 & 235621 & 9218689 & 16.07 & 16.34 & 972 & 171.4 & 0.176 \\
\hline 11 & 235908 & 9218707 & 235813 & 9218644 & 16.11 & 16.39 & 1008 & 114 & 0.113 \\
\hline 12 & 235718 & 9219148 & 235602 & 9219055 & 16.44 & 17.14 & 2520 & 148.7 & 0.059 \\
\hline 13 & 235898 & 9219130 & 235794 & 9219085 & 16.48 & 17.16 & 2448 & 113.3 & 0.046 \\
\hline & & & & & & & & $\begin{array}{l}\text { Kec. rata- } \\
\text { rata }\end{array}$ & 0.08 \\
\hline
\end{tabular}

Adapun model pola arus menggunakan software surface water modeling system (SMS) 10.0 pada saat surut menuju pasang dan saat pasang memuju surut disajikan pada gambar berikut ini (Gambar
5). Gradasi warna menunjukkan kecepatan arus sedangkan arah tanda panah menunjukkan arah arus. Pada saat surut menuju pasang dapat dilihat pada

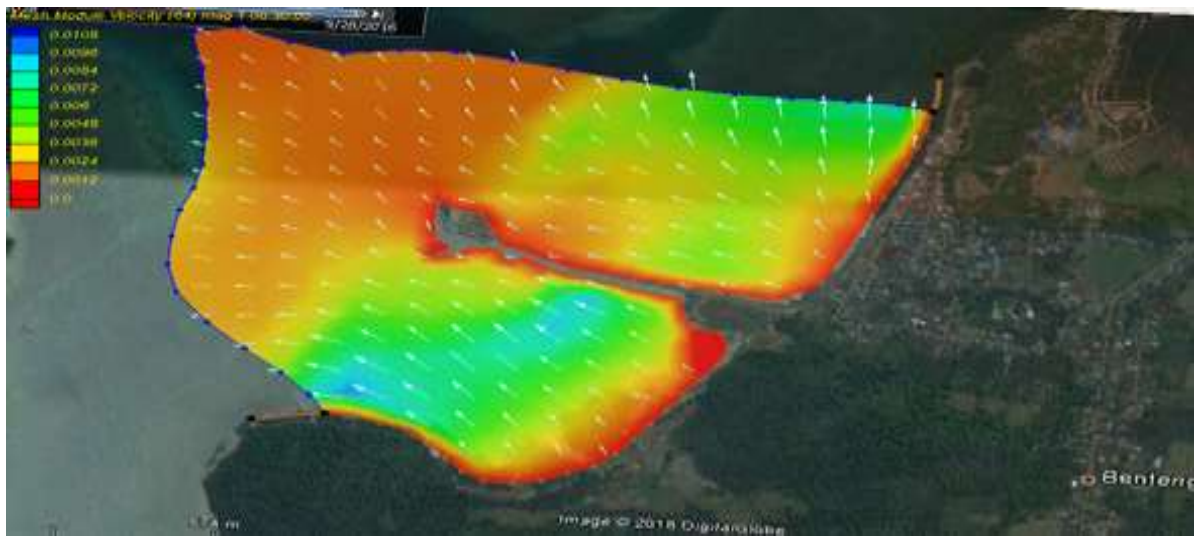

Gambar 5. Model pola arus pada saat Surut menuju Pasang (Sumber: Hasil Pengolahan Data Arus SMS 10.0) 
Gambar 6. Pada saat surut, arus di sekitar lokasi studi dominan bergerak dari tenggara ke barat laut dengan kecepatan rerata 0,009 $\mathrm{m} /$ detik. Dimana pada saat pasang di sekitar daerah studi arus bergerak dari barat laut menuju ke tenggara dengan kecepatan rerata yaitu $0,0084 \mathrm{~m} /$ detik. Antara pengukuran lansung dengan model numerik (SMS 10) dikarenakan kondisi laut yang begitu kompleks dengan pengaruh angin, pasang surut dan gelombang yang menjadi batasan dari software ini. Perbandingan antara pengukuran lapangan dan analisa model software SMS.10 di perlihatkan pada Tabel 2.

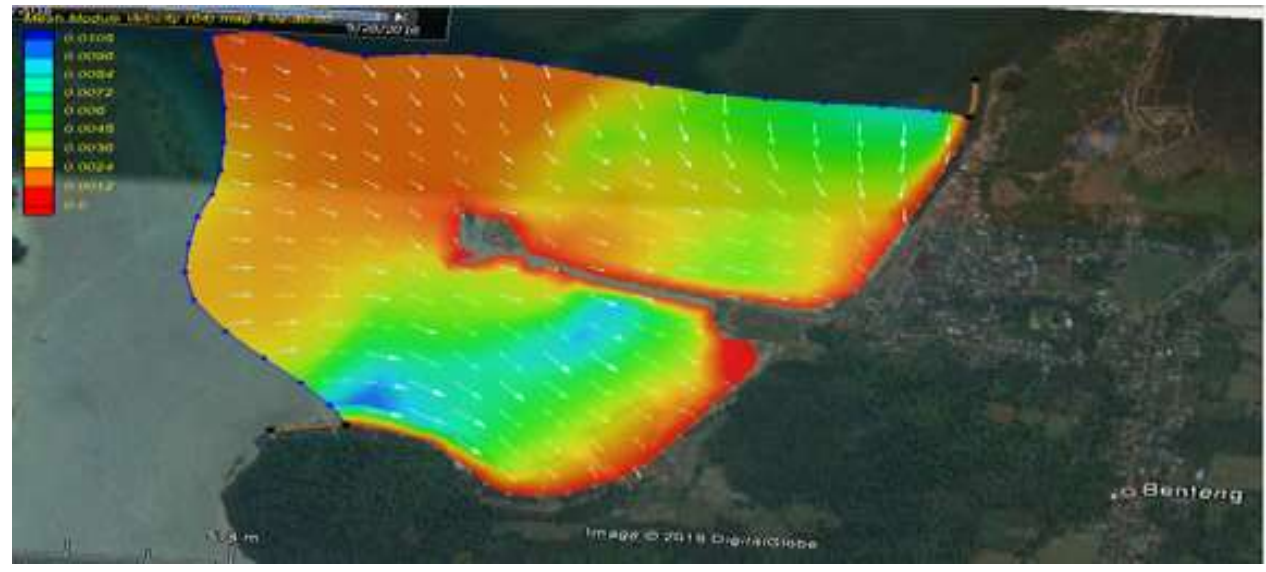

Gambar 6. Model Pola Arus pada Saat Pasang Menuju Surut (Sumber: Hasil Pengolahan Data SMS. 10.0)

Tabel 2 Hasil Perbandingan Pengukuran Arus pada Kondisi Lapangan dengan Software SMS.10 disekitar pelabuhan Jampea

\begin{tabular}{ccccc}
\hline No & Kondisi & Arah & $\begin{array}{c}\text { Hasil Pengukuran di } \\
\text { Lapangan }\end{array}$ & $\begin{array}{c}\text { Hasil Analisa } \\
\text { Software SMS.10 }\end{array}$ \\
\hline 1 & Saat Pasang & $\begin{array}{c}\text { Mengarah ke } \\
\text { Tenggara }\end{array}$ & $0,044 \mathrm{~m} /$ detik & $0,0084 \mathrm{~m} /$ detik \\
\hline 2 & Saat Surut & $\begin{array}{c}\text { Mengarah ke Barat } \\
\text { Laut }\end{array}$ & $0,08 \mathrm{~m} /$ detik & $0,009 \mathrm{~m} /$ detik
\end{tabular}

(Sumber: Hasil Olahan Data)

\section{KESIMPULAN DAN SARAN KESIMPULAN}

1. Kondisi batimetri pada areal sekitar pelabuhan Jampea termasuk kategori pantai yang landai dimana pesisir atau tepi laut yang daratannya menurun sedikit demi sedikit ke arah laut yang mengakibatkan pengaruh pasang surut dengan akan sangat jauh keluar menuju ke laut.
2. Kondisi Arus disekitar pelabuhan Jampea lebih dipengaruhi oleh arus pasang maupun arus surut dimana dari hasil penelitian kecepatan rata-rata arus pada saat menjelang pasang lebih besar dibandingkan pada saat surut.

\section{UCAPAN TERIMA KASIH}

Terima kasih penulis sampaikan kepada Direktur Politeknik Pertanian Negeri 
Pangkajene dan Kepulauan beserta jajarannya dan Ketua Pusat Penelitian dan Pengabdian Masyarakat Politeknik Pertanian Negeri Pangkajene dan Kepulauan yang telah menyediakan dana untuk pelaksanaan penelitian ini melalui anggaran biaya penerimaan Negara bukan pajak (PNBP) tahun anggaran 2019.

\section{DAFTAR PUSTAKA}

Bagus, B., 2013. Pemetaan Batimetri 3 D Perairan Pulau Panggang Kepulauan Seribu Menggunakan Citraworldview-2. Skripsi Departemen Ilmu dan Teknologi Kelautan Fakultas Perikanan dan Teknologi Kelautan Kelautan Institut Pertanian Bogor.

Becker dan Sandwell 2008. Global estimates of seafloor slope from singlebeam ship soundings. Journal of Geophysical Research. $113: 1-14$

Dewantoro,A. 2012. Analisis Ketelitian Hasil Perairan Dangkal Menggunakan Multibeam Echosounder (Studi Kasus: Suvei di Perairan Muara Karang - Teluk Jakarta). Laporan Tugas Akhir Jurusan Teknik Geodesi (Undip), Semarang.

Dewi LS, Ismanto A dan Indrayanti E. 2015. Pemetaan batimetri menggunakan singlebeam echosounder di perairan Lembar, Lombok Barat, Nusa Tenggara Barat. Jurnal Oseanografi. 4 (1): 10-17

Djunarsah, E., Poerbandono. 2005. Survei Hidrografi. Bandung: Refika Aditama. 166 hal.
Haryono. 2001. Pengantar Penentuan Posisi Horisontal Untuk Survey Rekayasa Laut. Buku 1, Jurusan Teknik Geodesi Fakultas Teknik UGM. Yogyakarta. hlm 5-18.

Prayitno., A.S., 2014. Makalah Survei Hidrografi Program Studi Teknik Sipil Universitas 17 Agustus Semarang.

Siebold, E., and W. H. Berger., 1993. The Sea Floor. An Introduction to Marine Geology. Second Edition Springer-Verlag Berlin. Jerman. $350 p$

Simmonds dan Maclennan 2001. Fisheries acoustics theory and practice second edition. Blackwell Science, Victoria. p 71 